Original Research Article

\title{
Knowledge attitude and practice of pharmacovigilance among nursing professionals in a tertiary care teaching hospital in Dehradun, Uttarakhand
}

\author{
Taruna Sharma ${ }^{1}$, D. C. Dhasmana ${ }^{1}$, Rajendra Sharma ${ }^{1}$, Suman Bala ${ }^{1}$, \\ Upasana Sharma $^{1}$, Upma George ${ }^{2}$
}

\begin{abstract}
${ }^{1}$ Department of Pharmacology,
${ }^{2}$ Department of Nursing,

Himalayan Institute of Medical

Sciences, SRHU, Jolly Grant,

Dehradun 248016, Uttarakhand, India
\end{abstract}

Received: 10 December 2016

Revised: 07 January 2017

Accepted: 09 January 2017

*Correspondence to:

Dr. Rajendra Sharma,

Email:

rajendra.sharma77@gmail.com

Copyright: (C) the author(s), publisher and licensee Medip Academy. This is an openaccess article distributed under the terms of the Creative Commons Attribution NonCommercial License, which permits unrestricted noncommercial use, distribution, and reproduction in any medium, provided the original work is properly cited.

\begin{abstract}
Background: Pharmacovigilance deals with identification, assessment and prevention and reporting of adverse drug reaction (ADR), play a pivotal role in ensuring safe use of drugs. However, in spite of having well established ADR reporting system in India and worldwide, the ADR underreporting is a big challenge till date. It is therefore very important to assess the level of awareness of Pharmacovigilance among healthcare professionals to identify the factors affecting ADRs reporting. The objective of the study was to evaluate knowledge, attitude and practice of pharmacovigilance among nursing professionals in a tertiary care teaching hospital in Dehradun, India.

Methods: It was a cross sectional observational study conducted at HIMS over a period of 1 year. Nursing professionals who work in internal medicine, Surgery, PAC and intensive care unit (ICU) were included in this study. A selfadministered questionnaire comprising of 15 items related to ADRs and Pharmacovigilance programme of India (PvPI) activity was provided to them and sufficient time to fill the questionnaire was given. The completely filled questionnaire was collected and data was analyzed using SPSS ver.20.0.

Results: A total of 415 participants were included in the study. The mean age of the participant was 28.52 years. The number of female was more than male participants. Majority of participant $(56 \%)$ couldn't answer the meaning of pharmacovigilance. Only $25 \%$ participants were aware about ADR reporting process to ADR monitoring centre (AMC). Although majority of the participants understand the necessity of ADR reporting and aware about AMC centre and PvPI, but most of them showed unfamiliarity about ADR reporting form and previous experience of any kind of ADR. The most common reason for not reporting the ADR was difficulty in deciding the nature of adverse effects (AE) (44\%) followed by lack of time (30\%). Majority of participant $(67 \%)$ denied any previous pharmacovigilance training and almost all (98\%) have shown their interest in PvPI training.

Conclusions: Nursing professionals in our hospital may lack adequate knowledge about ADR reporting and may need more education and training on the National Pharmacovigilance System and ADR reporting process.
\end{abstract}

Keywords: Knowledge-Attitude-Practice, Nursing professional, Pharmacovigilance, PvPI

\section{INTRODUCTION}

According to World Health Organization (WHO), Pharmacovigilance is the "science and activities relating to the detection, assessment, understanding and prevention of the adverse effects (AE)". 1 The safety information about a drug is collected in phase-I of the clinical trial before approval of the drug and continues after the approval.

Pharmacovigilance is particularly concerned with adverse drug reactions (ADRs), which are officially described as: "A response to a drug which is noxious and unintended and which occurs at doses that are normally used for the 
prophylaxis, diagnosis or therapy of disease or for modification of physiological function". ${ }^{2}$ ADRs are fourth to sixth leading cause of death among the hospitalized patients and occur in every 0.3 percent to 7 percent of hospital admissions. ${ }^{3}$

The possible incidence of ADRs in India is estimated somewhere between $10-20 \%$ and in fewer cases i.e. cancer chemotherapy etc. even increased to $70 \%$ and above. On the contrary the ADRs reporting rate in India lies below $1 \%$ as against the world rate of $5 \% .^{4}$ The goal of Pharmacovigilance Program of India (PvPI) which was initiated in July 2010 is that the benefits of use of medicine should outweigh the risks. ${ }^{5}$ However, pharmacovigilance has still to be developed in India. For this, we need constant surveillance, collection and analysis of the data regarding incidence, type of adverse events etc. related to drugs in a systematic manner. The active participation of healthcare professionals (HCPs) i.e. Nurse's, pharmacist's etc. is prerequisite in effective development of pharmacovigilance. The most common problem in spontaneous post- marketing surveillance programs is underreporting of ADRs which could be due to insufficient knowledge about drugs or ADRs reporting procedure etc.

Therefore, this study was planned to evaluate knowledge attitude and practice of pharmacovigilance among nursing professionals in a tertiary care teaching hospital in Dehradun India.

\section{METHODS}

This was a cross sectional observational study conducted at Himalayan Institute of Medical Sciences (HIMS) over a period of 1 year. Nursing professionals who work in internal medicine, surgery, pre-anaesthetic check-up (PAC) and Intensive care unit (ICU) were included in the study. The participants were informed about the aims of the study and their verbal consent was taken before including them in the study. A self-administered questionnaire was developed to assess knowledge and attitude towards ADRs and PvPI. This self-administered questionnaire comprised of 15 items which were centred around the pharmacovigilance and related activities. All the participants were briefed on the questionnaire by the principal investigator and provided sufficient time to fill the questionnaire freely without any undue influence. The filled questionnaire was collected and the responses to individual items were entered in to the data sheet and after completion of data entry the collected data was analysed.

\section{Statistical analysis}

The data obtained were entered in Microsoft excel spread sheet and evaluated for appropriateness. The various parameters such as sex distribution, professional status, educational qualifications, and the KAP responses were analyzed.

\section{RESULTS}

A total of 415 participants were included in the study. The mean age of the participant was 28.52 years. The number of female was more than male participants. Majority of participant $(56 \%)$ couldn't answer the meaning of pharmacovigilance. Only $25 \%$ participants were aware about ADRs reporting process to ADR monitoring centre (AMC centre). Although majority of the participants understand the necessity of ADRs reporting and aware about AMC centre and PvPI, but most of them showed unfamiliarity about ADRs reporting form and previous experience of any kind of ADRs. Majority of participant $(67 \%)$ denied any previous pharmacovigilance training and almost all (98\%) have shown their interest in PvPI training. The responses to individual items have been depicted in Figure 1.

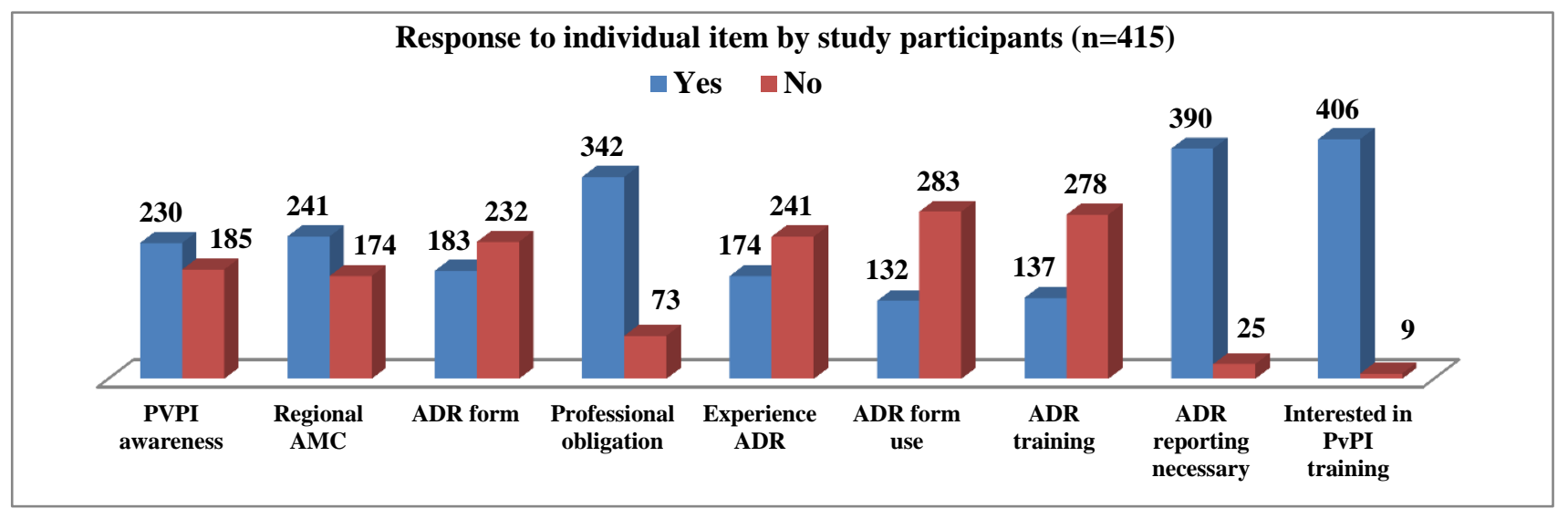

Figure 1: Response to individual item by study participants.

While assessing their perception regarding different aspects on pharmacovigilance related activities i.e. whom to report, what to report, treatment of ADRs and professional responsibility etc. alarming responses were 
obtained. On being asked about reason for not reporting the ADRs most of the participants reported difficulty in deciding the nature of $\mathrm{AE}(44 \%)$ whether related to drug or not followed by lack of time (30\%). Majority of participant $(67 \%)$ reported that both Suspected unexpected serious adverse reaction (SUSAR) and well known AE should be reported. Just $24.8 \%$ participant told that AE should be reported to AMC only however $20 \%$ told that AE should be reported to Clinician only. The details are depicted in Table 1.

Table 1: Perception on PV related activity among study participant $(n=415)$.

\begin{tabular}{|lllll|}
\hline \multirow{2}{*}{ Professional responsibility } & All & Doctor & Nurses & Pharmacist \\
\hline & SUSAR & $37(8.9 \%)$ & $76(18.3 \%)$ & $15(3.6 \%)$ \\
\hline What to report & $66(15.9 \%)$ & Well known AE & Both & None \\
\hline & AMC & Clinician & Both & $6(1.4 \%)$ \\
\hline Whom to report & $103(24.8 \%)$ & $83(20.0 \%)$ & $220(53.0 \%)$ & None \\
\hline & New symptom & No action & Stop drug & Wait for clinician's order \\
\hline T/t of ADRs & $16(3.85 \%)$ & $2(0.5 \%)$ & $381(91.8 \%)$ & $16(3.85 \%)$ \\
\hline & Difficult to decide & Lack of time & No renumeration & Single AE has no impact \\
\hline Reason for not report & $183(44.1 \%)$ & $123(29.6 \%)$ & $51(12.3 \%)$ & $58(14.0 \%)$ \\
\hline
\end{tabular}

\section{DISCUSSION}

Pharmacovigilance is an integral and essential part of patient care. Moreover it is an evidence driven speciality wherein healthcare professionals are supposed to detect and report the suspected ADRs, which help to identify the new reactions, record the frequency and associated risk factors, with a view to prevent future ADRs. Therefore, the most important outcome of the pharmacovigilance is the prevention of patients being affected unnecessarily by negative consequences of pharmacotherapy. ${ }^{6}$ For the detection of ADRs and to prohibit the use of several drugs from the market, pharmacovigilance programmes have played a major role. Considering the aforementioned points National Pharmacovigilance Programme has launched in India. ${ }^{7}$ However, inadequate reporting of ADRs is a major hurdle for pharmacovigilance programme not only in India but even in developed countries where pharmacovigilance programmes are well established. ${ }^{8}$ The possible reason for underreporting could be inappropriate knowledge and awareness about pharmacovigilance activities among health care professionals. By increasing the knowledge and awareness of healthcare professionals regarding ADRs monitoring and pharmacovigilance programmes, the problem of underreporting can be well controlled. ${ }^{8}$ Similarly, training courses to health professionals including nurses and health professionals can also be useful. Our study has evaluated Knowledge attitude and practice of pharmacovigilance among nursing professionals in a tertiary care hospital. Overall scoring was low. Just $58 \%$ participants had knowledge about ADRs monitoring centre (AMC) at HIMS, Uttarakhand. Our study depicts low level of awareness about pharmacovigilance and approaches of ADRs reporting among all the participants, which indicated towards distressing situation and requirement of immediate attention for improvement. Similar results were highlighted by another study which also emphasized for educational interventions for healthcare professionals. ${ }^{8}$ On the contrary, an observational study conducted in paediatric hospital found that despite good knowledge about ADR reporting, lack of reporting facilities was the cause of underreporting. ${ }^{9}$ The training programme therefore should cover the reporting procedure and method of filling ADR reporting form along with the knowledge on location of pharmacovigilance centres. Observations regarding attitude of nursing professionals towards pharmacovigilance showed, that $94 \%$ participants agreed to include ADR reporting in clinical practice, $82 \%$ nursing professionals think that it's a professional obligation, 98\% nursing professionals are ready to take part in training for PvPI. From our study, it has been noticed that majority of nursing professionals have accepted the necessity of awareness programme so that National Pharmacovigilance programmes can be effectively implemented.

\section{CONCLUSION}

This survey on pharmacovigilance and ADRs reporting among nursing professional suggests that the nursing professional in this region lack knowledge of the facts about ADRs reporting and may need more information on the ADRs reporting process and National Pharmacovigilance System. Nursing professionals should also be educated about methods of detecting, preventing and reporting of ADRs so that they can be helpful in prevention of ADRs.

\section{Funding: No funding sources}

Conflict of interest: None declared

Ethical approval: The study was approved by the Institutional Ethics Committee 


\section{REFERENCES}

1. World Health Organization. Safety of Medicines. A guide to detecting and reporting adverse drug reactions. Why health professionals need to take action. Geneva World Health Organization; 2002.

2. Vallano A, Cereza G, Pedròs C, Agustí A, Danés I, Aguilera C, et al. Obstacles and solutions for spontaneous reporting of adverse drug reactions in the hospital. Br J Clin Pharmacol. 2005;60(6):653-8.

3. Jaibu AE, Venkateswaramurthy N, Sambathkumar R. The knowledge, perceptions and practice of pharmacovigilance among community pharmacists in Kumarapalayam, Tamil Nadu. Int J Adv Pharm Gen Res. 2015;3(2):1-11.

4. Prakash S. Pharmacovigilance in India. Indian J Pharmacol. 2007;39:123-3.

5. Gupta YK. Ensuring Patient Safety - Launching the New Pharmacovigilance Programme of India. Pharmatimes. 2010;42(8):21-6.

6. Rehan HS, Vasudev K, Tripathi CD. Adverse drug reactions monitoring: Knowledge, attitude and practices of medical students and prescribers. The National Medical Journal of India. 2002;15(1):24-6.
7. Gaikwad NR, Yadav SS, Patil AB, Manjrekar PV, Jha RK. Awareness about adverse drug reactions monitoring among prescribers of rural teaching hospital of central India .JDMIMSU. 2009;4(3):1736.

8. Palaian S, Ibrahim MI, Mishra P. Health professionals knowledge, attitude and practices towards Pharmacovigilance in Nepal. Pharmacy practice. 2011;9(4):228-35.

9. Muraraiah S, Rajarathna K, Sreedhar D, Basavalingu $\mathrm{D}$, Jayanthi CR. A questionnaire study to assure the knowledge, attitude and practice of Pharmacovigilance in a paediatric tertiary care centre. Journal of Chemical and Pharmaceutical Research. 2011;3(6):416-22.

Cite this article as: Sharma T, Dhasmana DC, Sharma R, Bala S, Sharma U, George U. Knowledge attitude and practice of pharmacovigilance among nursing professionals in a tertiary care teaching hospital in Dehradun, Uttarakhand. Int J Basic Clin Pharmacol 2017;6:414-7. 